Journal of Engineering and Applied Sciences 14 (Special Issue 4): 7297-7301, 2019

ISSN: 1816-949X

(C) Medwell Journals, 2019

\title{
Enhancement of Fischer-Tropsch Process using Four Different Types of Polymers Over Nano Iron-Paraffin/Polymer System
}

\author{
Abdulqadier Hussien Al Khazraji and Ghalib A. Atiya \\ Department of Chemistry, College of Education for Pure Science, University of Diyala, Baqubah, Iraq \\ ahnhkm@yahoo.com, +9647735115663
}

\begin{abstract}
Four Fe-paraffin/polymers catalysts were prepared by thermal decomposition method, i.e., Fe-paraffin/PEG, Fe-paraffin/SBR, Fe-paraffin/PP and Fe-paraffin/PC and their Fischer-Tropsch Synthesis (FTS) activity and selectivity. The behavior of them were investigated and compared using a slurry reactor. We observed that the catalyst based on Propylene (PP) had the lowest initial activity but have more selectivity compared with other catalysts. The catalyst based on Polyethylene Glycol (PEG) and Styrene-Butadiene Rubber (SBR) showed enhancement of production of light olefins compared with the catalyst based on Propylene (PP) and Polycarbonate (PC). The obtained nanocomposites catalysts based on Fe-paraffin/Polymers (Fe-p/P) system have been characterized with $\mathrm{AFM}, \mathrm{XRD}$ and have proven to be a dispersed form of $\mathrm{Fe}_{3} \mathrm{O}_{4}$ oxide nanoparticles. Methane, light olefins and $\mathrm{CO}_{2}$ productivity and selectivity increased with time and temperature for all catalysts. The system Fe-paraffin/Polyethylene Glycol (Fe-p/PEG) have a great impact on $\mathrm{CO}$ conversion that reached up to $74 \%$ and a high yield of total hydrocarbons of $62 \mathrm{~g} / \mathrm{m}^{3}$.
\end{abstract}

Key words: Fischer-tropsch synthesis, Fe-paraffin/polymers catalyst, slurry reactor, SBR, polycarbonate, polyethylene glycol

\section{INTRODUCTION}

The high energy demand, oil prices and environmental pollution have received remarkable attention resulted to develop alternative technologies for the conversion of light hydrocarbons Gas To Liquid (GTL) for the manufacture of transportation fuels (Rahimpour et al., 2012; Rafiee and Hillestad, 2012; Glasser et al., 2012). In such GTL process, Fischer-Tropsch Synthesis (FTS) plays an essential role for reforming synthesis gas $\left(\mathrm{CO}\right.$ and $\mathrm{H}_{2}$ mixture in gas form) for the production of clean fuels, essential chemicals and other industrial hydrocarbons raw materials. The requirements for developing an effective catalyst have arisen, since, multistage reactor system is the most competitive challenge in FTS. Catalysts based on iron and cobalt are used for FTS mostly. The iron one have selectivity and activity for the FTS process and for the reaction of Water-Gas-Shift (WGS) as well. This can be considered an ideal for converting carbon monoxide-lean (low $\mathrm{H}_{2} / \mathrm{CO}$ ratio) which normally derived from coal (Bae et al., 2009; Pour et al., 2010). Previous research shows a slurry of polymer-metal based catalysts have a great impact on stability, activity and selectivity of the catalysts compared to metal component alone
(Kulikova et al., 2015a, b). Whereas catalyst composition exerts the greatest influence on the nanoparticles size distribution. Also, it is accepted that because of kinetic and thermodynamic limitations of such sort of reactions, bi-component catalysts system shall be more capable to boost up the value of the low carbon olefins and liquid hydrocarbons (Cooper and Frost, 1990; Mirzaei et al., 2010; Kulikova et al., 2015a, b). Many studies have indicated an improvement in selectivity and/or activity by using a metal dispersion in the polymer matrix to form a FTS catalysts (Kulikova et al., 2015a, b). Bondarenko et al. (2016) had proven that the addition of specific polymers would lead to increase the catalyst activity for both $\mathrm{CO}$ conversion and hydrocarbon productivity up to some level of degrees.

In this study, Four Fe-paraffin/Polymers (Fe-p/P) catalysts were prepared by thermal decomposition preparation technique to investigate activity and selectivity behavior during the FTS in the three-phase slurry reactor.

\section{MATERIALS AND METHODS}

Catalyst preparation: The catalyst based on iron was prepared by thermal decomposition method as follows, an

Corresponding Author: Abdulqadier Hussien Al Khazraji, Department of Chemistry, College of Education for Pure Science, University of Diyala, Baqubah, Iraq, ahnhkm@yahoo.com 
aqueous solutions $\mathrm{Fe}\left(\mathrm{NO}_{3}\right)_{3}$. The $9 \mathrm{H}_{2} \mathrm{O}(43.23 \mathrm{~g})$ was dissolved in distilled water $(20 \mathrm{~mL})$, this was added drop wise to the paraffin $(100 \mathrm{~mL}) /$ polymer $(10 \mathrm{~g})$ matrix under $\mathrm{Ar}$ and stirring at $280^{\circ} \mathrm{C}$, for $4 \mathrm{~h}$. This was following by downloaded the aged suspension nanoiron catalyst into slurry reactor. The FTS process was done with the catalyst suspended under the following conditions; pressure of $2(\mathrm{MPa})$ and a syngas dose increment of $1.00-$ $2.00 \mathrm{~L} /\left(\mathrm{g}\right.$ cat. $\mathrm{h}$ ) (syngas with a molar ratio $1: 1$ of $\mathrm{CO}: \mathrm{H}_{2}$ ) the reaction mixture was warm slowly from $220-{ }^{\circ} \mathrm{C}\left(20^{\circ} \mathrm{C}\right.$ interval each $12 \mathrm{~h}$ ).

\section{Catalyst characterization}

Particle size: Nanoparticles size determined by the means of scattering of dynamic light on a Malvern Zetasizer Nano ZS instrument. Sample preparation consisted of the dissolution of the sample $0.01 \mathrm{~g}$ in hexane $10 \mathrm{~mL}$ with the sodium dioctyl sulfosuccinate 5 wt. $\%$ was added as a surfactant.

Microscopy: The samples were analyzed using AtomicForce (AFM) microscopy, an AFM type spectrometer with a PX Ultra multi-frequency controller and a Hybrid ${ }^{\mathrm{TM}}$ method controller. The probes used had the characteristics; CSG10. Freq. $=8.5 \mathrm{kHz}, \mathrm{k}=0.07 \mathrm{~N} / \mathrm{m}$ NSG01. Freq $=187.2 \mathrm{kHz}, \mathrm{k}=3.9 \mathrm{~N} / \mathrm{m}$. All measurements were performed using the Hybrid technique using the DMT Model to determine the nanoparticles in the inner side of the samples, the surface layer of paraffin was removed by hexane.

XRD analysis: The studies were carried out on a Shimadzu XRD-7000 apparatus using $\mathrm{Cu}$ Ka radiation. The voltage was $40 \mathrm{kV}$, the current strength was $30 \mathrm{~mA}$ and the scan rate was $2 \mathrm{sec}$. The purpose of this analysis was to obtain information on the phase composition of iron and paraffin compounds in the samples. By the intensity of the peaks and their position, using the image to the base of ethelon X-rays, a qualitative analysis was carried out.

\section{RESULTS AND DISCUSSION}

FTS reaction: The FTS was conducted with suspended catalyst at a range temperature of $220-320^{\circ} \mathrm{C}$. The best yield of hydrocarbons was indicated at $300-320^{\circ} \mathrm{C}$ for all catalysts as well as a high formation of methane, light gases and $\mathrm{CO}_{2}$ were also formed (Fig. 1-3). The selectivity towards unwanted products, like $\mathrm{CO}_{2}$ and methane, dropped down quickly to $\mathrm{CO}_{2} 15 \%$ and methane $10 \%$ while those towards $\mathrm{C} 5+$ noticed a big change to more than 50 and $60 \%$, respectively (Fig. 4). Of course this is a prove
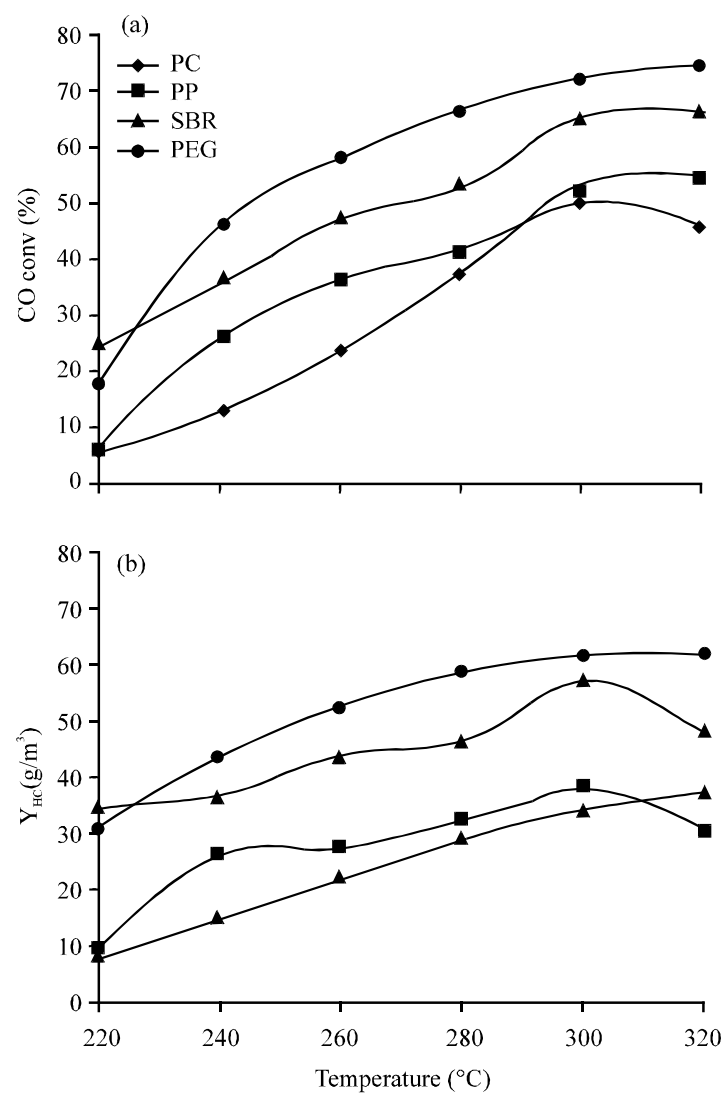

Fig. 1: $\mathrm{CO}$ conversion and formation of hydrocarbon liquid over nanoiron catalysts: a) $\mathrm{CO}$-conversion and b) Yield of liquid hydrocarbons (C5+)

that the addition of polymer to the Fe-nanoparticales plays an essential rules to drive the reaction towards the desired products.

Characterization of the nanocomposites: The nanoparticles were prepared in paraffin/polymer as a matrix via. method described earlier by Kulikova et al. $(2015 \mathrm{a}, \mathrm{b})$. Also the preparation of iron oxide nanoparticle by dissolving of iron (III) nitrate $\left(\mathrm{Fe}\left(\mathrm{NO}_{3}\right)_{3} .9 \mathrm{H}_{2} \mathrm{O}\right)$ in a molten paraffin/polymer matrix where polymer such as; Polyethylene Glycol (PEG), Styrene-Butadiene Rubber (SBR), Polypropylene (PP) and Polycarbonate (PC). The particles size distribution of the synthesized suspensions of catalysts before and after FTS are shown in Table 1.

All catalysts showed deformation and aggregation of nanoparticles. Deformation and aggregation depend on polymer type. The most effective catalysts have the least deformation and particle aggregation value and this is a clear indication of the stability of iron oxide $\left(\mathrm{Fe}_{3} \mathrm{O}_{4}\right)$ on the surface of the paraffin/polymer matrix compared to the less effective catalysts that gave greater distortion and aggregation of the particles. 

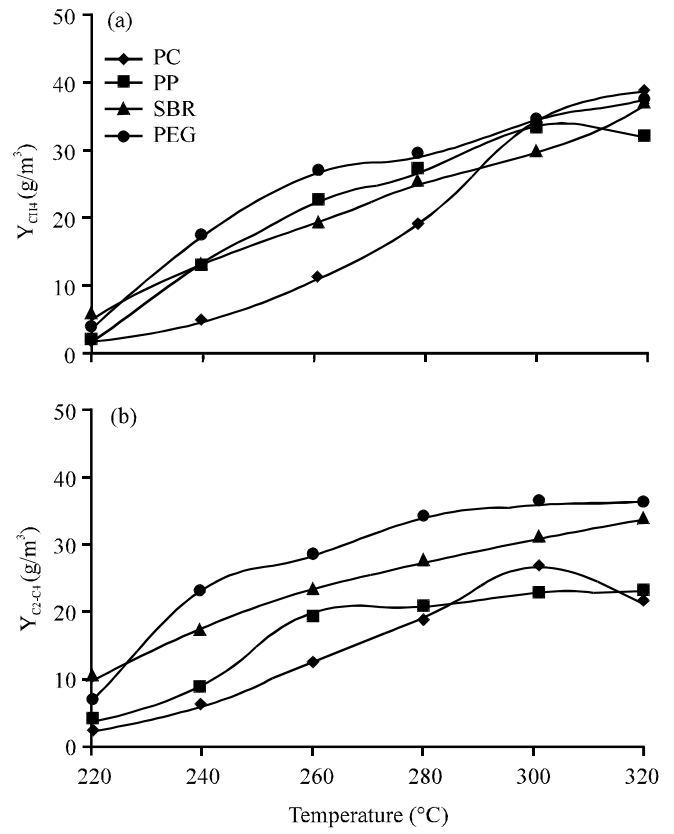

Fig. 2: Hydrocarbons gases formation over nanoiron catalysts: a) CH4-formation and b) $\mathrm{C} 2-\mathrm{C} 4-$ formation
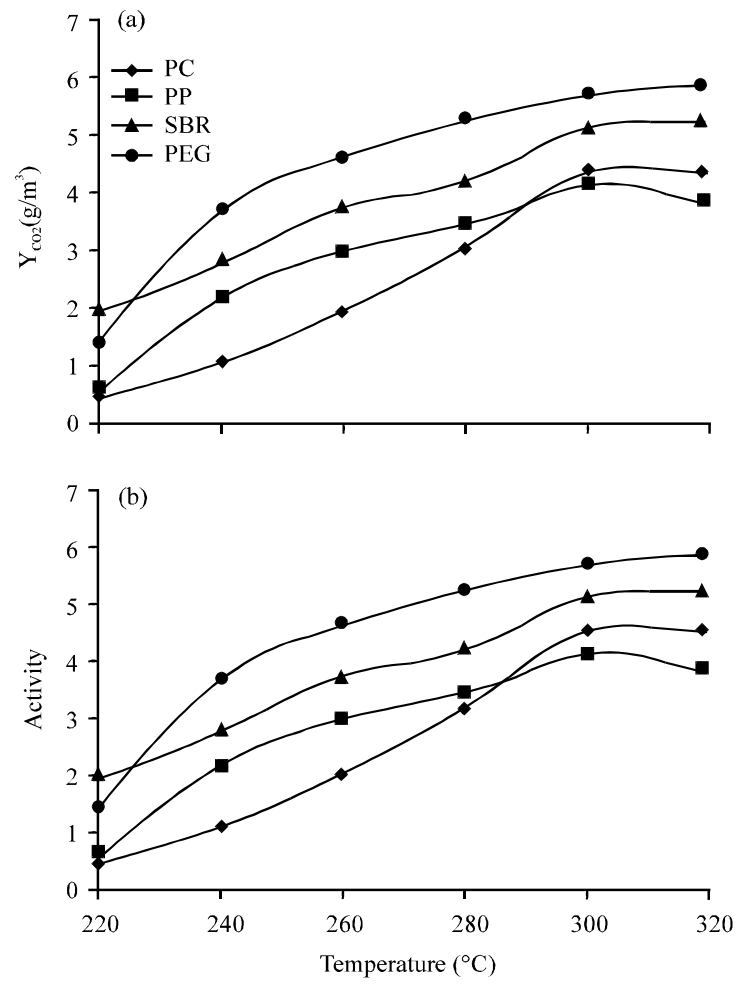

Fig. 3: $\mathrm{CO} 2$ formation and catalytic activity of nanoiron catalysts: a) CO2-formation and b) Catalytic activity
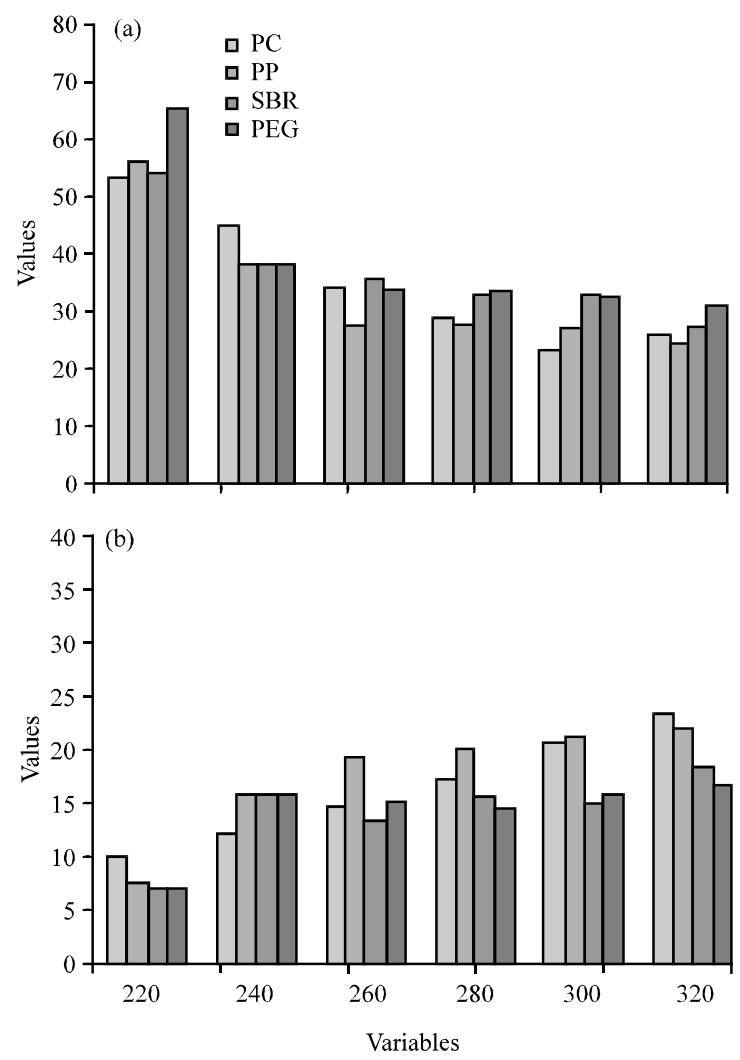

Fig. 4: C5+ and methane selectivity over nanoiron catalysts: a) C5+ selectivity and b) $\mathrm{CH} 4$ selectivity

Table 1: Particle size effect on FTS process of the working of catalytic

\begin{tabular}{|c|c|c|c|c|}
\hline \multirow[b]{3}{*}{ Nano-catalyst $(\mathrm{Fe}-\mathrm{p} / \mathrm{P})$} & \multicolumn{4}{|c|}{$\begin{array}{l}\text { Changes in particles size (nm) of iron nano-catalyst } \\
\text { system before and after FTS }\end{array}$} \\
\hline & \multicolumn{2}{|c|}{ Before process } & \multicolumn{2}{|c|}{ After process } \\
\hline & $\mathrm{nm}$ & Content $(\%)$ & $\mathrm{nm}$ & Content $(\%)$ \\
\hline \multirow[t]{2}{*}{ Fe-p/PEG } & 181.0 & 9.0 & 220.0 & 2.0 \\
\hline & 655.0 & 91.0 & 842.0 & 98.0 \\
\hline \multirow[t]{2}{*}{ Fe-p/PP } & 2.0 & 8.0 & 289.0 & 14.0 \\
\hline & 488.0 & 92.0 & 953.0 & 86.0 \\
\hline \multirow[t]{2}{*}{ Fe-p/SBR } & 312.0 & 6.0 & 1008.0 & 93.0 \\
\hline & 644.0 & 94.0 & 2043.0 & 7.0 \\
\hline $\mathrm{Fe}-\mathrm{p} / \mathrm{PC}$ & 85.0 & 6.0 & 899.0 & 93.0 \\
\hline
\end{tabular}

\section{The surface morphology}

X-ray diffraction: Figure 5 represents the analysis of the XR-diffraction of all samples showed that have peaks indicating two phase of iron oxide $\mathrm{Fe}_{3} \mathrm{O}_{4}$ and $\delta-\mathrm{FeOOH}$. The catalyst based on polycarbonate and propylene were showed very weak peaks and the presence of a amorphous refer to $\delta$-FeOOH compared as catalyst based on polyethylene glycol and styrene butadiene rubber where it was clear that there are peaks due to iron oxide $\mathrm{Fe}_{3} \mathrm{O}_{4}$ and varying degrees between the catalytic. In the case of polyethylene more powerful and clear at 20:30, 


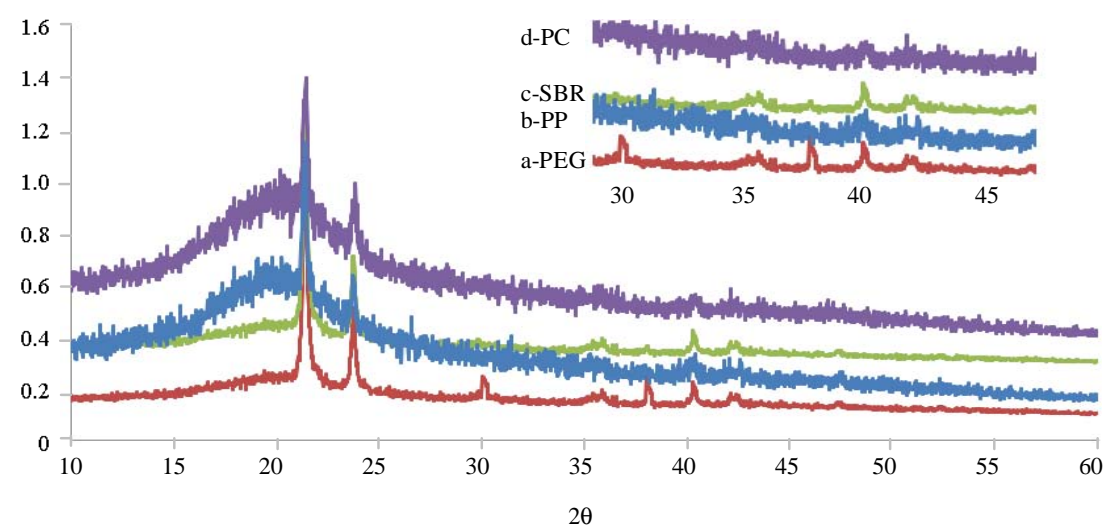

Fig. 5: XRD patterns of Fe-p/P catalysts based on: a) PEG; b) PP; c) SBR and d) PC
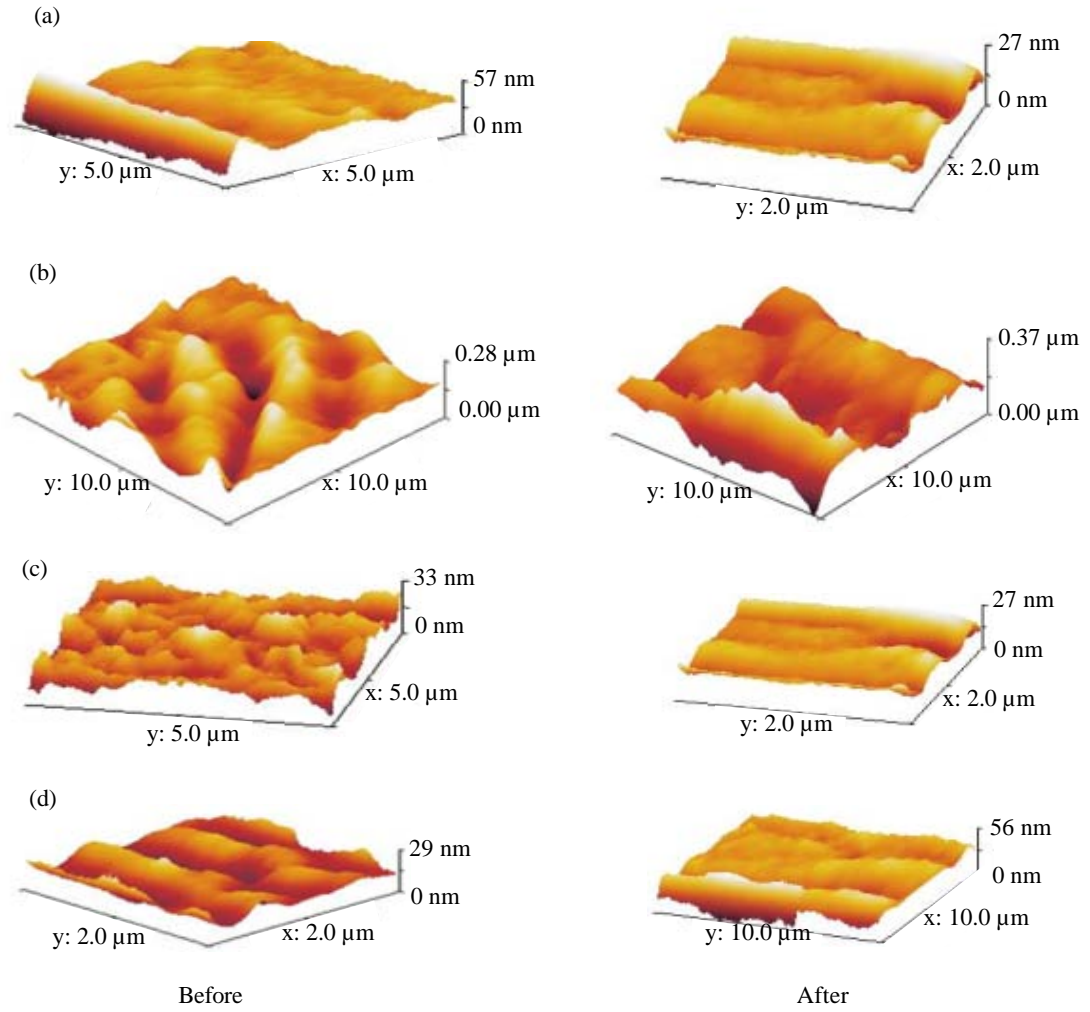

Fig. 6: AFM analysis of surface morphology of used system Fe-p/P catalysts before and after washed with hexane: a) PC; b) PEG; c) SBR and d) PP

38 and $42^{\circ}$ which may refer to magnetite $\left(\mathrm{Fe}_{3} \mathrm{O}_{4}\right)$ (Park et al., 2008; Zhang et al., 2007), this fact a strengthens peaks of catalysts are very effective compared as catalyst based on polycarbonate and propylene in the process of Fischer-Tropsch.

Atomic force microscopy analysis: The AFM analysis (Fig. 6) allows to evaluate the morphology and distribution of the nano iron, showing the existence of a close dependence between the distribution of the nanoiron and the polymer type during the synthesis of the catalyst.

The morphology of the surface of Fe-p/PEG looks more regular features with nearly sharp tips up wording outer of the surface of the particles and an approximate distances from surrounding tips and $\mathrm{Fe}-\mathrm{p} / \mathrm{SBR}$ catalysts clearly showing more regular and the distance between them about $2.66 \pm 0.44 \mu \mathrm{m}$ with depth of $0.28 \mu \mathrm{m}$ or in 
another words $17 \mathrm{tips} / 100 \mu \mathrm{m}^{2}$ of area. And similar things appeared of the catalyst Fe-p/SBR with less regularity but more roughness. Whereas the other two catalysts the $\mathrm{Fe}-\mathrm{p} / \mathrm{PC}$ shows rounded tip groves with averaged distance between the of $2.125 \pm 0.375 \mu \mathrm{m}$ and the $\mathrm{Fe}-\mathrm{p} / \mathrm{PP}$ shows similar surface feature with parallel groves of $1.8 \mu \mathrm{m}$ between each other. Also Fig. 5 reveled that catalyst Fe-p/PEG and Fe-p/SBR both have more than one phase of crystallinity which improve the regularity of the surface of the catalyst particles. So, for the catalyst $\mathrm{Fe}-\mathrm{p} / \mathrm{PEG}$, we believe with such pattern have great impact on $\mathrm{C}_{5+}$ selectivity at $220^{\circ} \mathrm{C}$ compared with other catalysts as shown in Fig. 6 a.

\section{CONCLUSION}

Four $\mathrm{Fe}-\mathrm{p} / \mathrm{P}$ catalysts were prepared by thermal decomposition preparation technique. The catalyst $\mathrm{Fe}-\mathrm{p} / \mathrm{PEG}$ was the best for $\mathrm{C}_{5+}$ among the others at $220^{\circ} \mathrm{C}$ and the Fe-p/PC, Fe-p/PP, Fe-p/SBR investigated from activity and selectivity behavior during FTS in a slurry reactor. The following results can be concluded.

As comparison between the four Fe-paraffin/polymer catalysts; the $\mathrm{CO}$ conversions and liquid hydrocarbons formation of catalysts based on normal polymer ( $\mathrm{PP}$ and PC ) were the lowest and the $\mathrm{CO}_{2}$ formation reduced to much better than the other two PEG and SBR polymer based catalysts.

All catalysts showed deformation and aggregation of nanoparticles after FTS reaction. Fe-p/PP and Fe-p/PC catalysts suppressed the methane and $\mathrm{CO}_{2}$ formation better than the two other catalysts (Fe-p/PEG and Fe-p/SBR).

The Fe-p/PP and Fe-p/PC catalysts suppressed the methane formation far better than the two other catalysts. All catalysts led to reduced selectivity of liquid hydrocarbons at high temperature, at same time enhance selectivity $\mathrm{CH}_{4}$ when the temperature rises from $220^{\circ} \mathrm{C}$ up to $320^{\circ} \mathrm{C}$.

\section{ACKNOWLEDGEMENT}

The present research were carried out using the facilities and instruments of A.V. Topchiev Institute of Petrochemical Synthesis, Russian Academy of Sciences and supported by The President of Russian Federation.

\section{REFERENCES}

Bae, J.W., S.J. Park, S.H. Kang, Y.J. Lee and K.W. Jun et al., 2009. Effect of $\mathrm{Cu}$ content on the bifunctional Fischer-Tropsch Fe-Cu-K/ZSM5 catalyst. J. Ind. Eng. Chem., 15: 798-802.
Bondarenko, G.N., M.V., Kulikova, A.H. Al Khazraji, O.S. Dementieva and M.I. Ivantsov et al., 2016. [Kinetic models of Fischer-Tropsch synthesis in the presence of catalysts with nanoparticles of iron on polymer vlarry reactor matrices (In Russian)]. Nanoheterogeneous Catal., 1: 122-128.

Cooper, M.E. and J. Frost, 1990. New iron/nickel alloy catalyst for Fischer-Tropsch synthesis. Appl. Catal., 57: L5-L8.

Glasser, D., D. Hildebrandt, X. Liu, X. Lu and C.M. Masuku, 2012. Recent advances in understanding the Fischer-Tropsch Synthesis (FTS) reaction. Curr. Opin. Chem. Eng., 1: 296-302.

Kulikova, M.V., A. Al Kh, O.S. Dementieva, M.I. Ivantsov and V.R. Flid et al., 2015b. [Influence of the composition of a dispersion environment on the flow of fisher-trips synthesis in a three-phase system in the presence of iron-containing catalyst (In Russian)]. Petrochemistry, 55: 391-395.

Kulikova, M.V.E., M.I. Ivantsov, M.N. Efimov, L.M. Zemtsov and P.A. Chernavskii et al., $2015 \mathrm{a}$. Formation features of composite materials containing cobalt nanoparticles active in Fischer-Tropsch synthesis. Eur. Chem. Bull., 4: 181-185.

Mirzaei, A.A., A. Beigbabaei, M. Galavy and A. Youssefi, 2010. A silica supported Fe-Co bimetallic catalyst prepared by the sol/gel technique: Operating conditions, catalytic properties and characterization. Fuel Proc. Technol., 91: 335-347.

Mirzaei, A.A., M. Faizi and R. Habibpour, 2006. Effect of preparation conditions on the catalytic performance of cobalt manganese oxide catalysts for conversion of synthesis gas to light olefins. Appl. Catal. Gen., 306: 98-107.

Park, H., P. Ayala, M.A. Deshusses, A. Mulchandani and H. Choi et al., 2008. Electrodeposition of maghemite $\left(\gamma-\mathrm{Fe}_{2} \mathrm{O}_{3}\right)$ nanoparticles. Chem. Eng. J., 139: 208-212.

Pour, A.N., M.R. Housaindokht, S.F. Tayyari and J. Zarkesh, 2010. Fischer-Tropsch synthesis by nano-structured iron catalyst. J. Nat. Gas Chem., 19: 284-292.

Rafiee, A. and M. Hillestad, 2012. Staging of the Fischer-Tropsch reactor with an iron based catalyst. Comput. Chem. Eng., 39: 75-83.

Rahimpour, M.R., S.M. Jokar and Z. Jamshidnejad, 2012. A novel slurry bubble column membrane reactor concept for Fischer-Tropsch synthesis in GTL technology. Chem. Eng. Res. Des., 90: 383-396.

Zhang, Q.L., Y.C. Lin, X. Chen and N.Y. Gao, 2007. A method for preparing ferric activated carbon composites adsorbents to remove arsenic from drinking water. J. Hazard. Mater., 148: 671-678. 